\title{
Sosialisasi Olahraga Handball di SMP Muhammadiyah Pekajangan
}

\section{Safrina Audia Balfasa*, Adi Sapto Januar, Adetyo Andra Yuniarko, Achnaf Rauf Pasha, Gilang Nuari Paggraita}

Universitas Muhammadiyah Pekajangan Pekalongan

*Penulis korespondensi: safrinafina22@gmail.com

\begin{abstract}
Abstrak: Permainan bola tangan belum berkembang pesat seperti olahraga permainan sepakbola, bola basket dan bola voli. Hal ini dikarenakan kurangnya sosialisasi serta minimnya fasilitas dan perlengkapan yang dapat digunakan dalam permainan bola tangan, sehingga permainan ini kurang diminati oleh sebagian masyarakat, terutama para siswa di sekolah. Tujuan kegiatan pengabdian masyarakat ini adalah memberikan sosialisasi pada siswa tentang permainan bola tangan untuk menambah wawasan serta keterampilan siswa tentang permainan bola tangan. Metode yang digunakan dalam kegiatan ini adalah ceramah dan demonstrasi. Berdasarkan angket kepuasan yang diberikan kepada seluruh peserta ditemukan bahwa 85\% siswa merasa puas. Dalam hal ini, hasil yang telah dicapai dalam sosialisasi handball yaitu meningkatnya pengetahuan dan pemahaman siswa-siswi SMP Muhammadiyah mengenai olahraga handball yang dilakukan dalam bentuk presentasi materi serta meningkatnya keterampilan dasar teknik permainan handball.
\end{abstract}

Kata kunci: sosialisasi, handball, siswa SMP

\begin{abstract}
The game of handball has not developed rapidly, such as football, basketball and volleyball. This is due to the lack of socialization and the lack of facilities and equipment that can be used in handball games, so this game is less attractive to some people, especially students at school. The purpose of this activity is to provide socialization to students about handball games to increase students' insight and skills about handball games. The methods used in this activity are lectures and demonstrations. Based on the satisfaction questionnaire given to all participants, it was found that $85 \%$ of students were satisfied. In this case, the results that have been achieved in handball socialization are increasing knowledge and understanding of SMP Muhammadiyah' students about handball sports which are carried out in the form of material presentations and increasing basic skills of handball game techniques.
\end{abstract}

Keywords: socialization, handball, junior high school students

\section{Pendahuluan}

Aktivitas olahraga saat ini benar-benar sudah menjadi bagian dari kebutuhan masyarakat, baik pada masyarakat atau golongan dengan sosial ekonomi yang rendah sampai yang paling tinggi. Di antara materi pelajaran Pendidikan Jasmani, Olahraga, dan Kesehatan (PJOK) yang

Sosialisasi Olahraga Handball di SMP Muhammadiyah Pekajangan

Safrina Audia Balfasa, Adi Sapto Januar, Adetyo Andra Yuniarko, Achnaf Rauf Pasha, Gilang Nuari 
ada, materi permainan dan olahraga merupakan salah satu materi yang disukai oleh peserta didik, hal ini karena suasana yang dibangun sangat menarik dan menantang (Sumarsono dkk., 2019). Kegunaan akan pentingnya berolahraga sangat dirasakan oleh masyarakat berupa latihan olahraga yang teratur dalam rangka untuk kesegaran dan kesehatan jasmani.

Seseorang melakukan olahraga dengan tujuan untuk mendapatkan kesegaran jasmani. Pembelajaran aktivitas jasmani merupakan salah satu proses yang lebih spesifik dari pendidikan yang dilakukan dengan terencana, sistematis dan menggunakan pendekatanpendekatan yang sesuai dengan tujuan yang akan dicapai (Setiawan \& Rahmat, 2018). Pendidikan Jasmani, dalam proses pembelajaran materi pelajaran yang diajarkan salah satunya permainan bola tangan. Permainan bola tangan merupakan salah satu permainan olahraga yang kompleks dan mulai digemari siswa, khususnya bola tangan indoor (Mulyani, 2017). Permainan bola tangan ini tidak hanya diajarkan di sekolah tetapi juga diajarkan di perguruan tinggi keolahragaan sebagai salah satu mata kuliah wajib yang harus ditempuh oleh mahasiswa. Olahraga bola tangan merupakan permainan beregu dengan tujuan memasukkan bola lebih banyak ke gawang lawan (Rahayu dkk., 2020).

Olahraga bola tangan pada masa Yunani Kuno merupakan salah satu olahraga yang sampai saat ini dapat ditelusuri kebenaran sejarahnya dan telah berusia sangat tua. Sebuah fakta yang meyakinkan telah menunjukkan bahwa seorang laki-laki akan senantiasa lebih mahir menggunakan tangan daripada kakinya (Iskandar dkk., 2020). Sebagaimana telah diklaim oleh sejarawan olahraga terkenal, ia memainkan bola tangan jauh lebih awal dibandingkan sepak bola, walaupun dengan peraturan yang masih kuno. Permainan bola tangan yang dimainkan pada masa Yunani kuno merupakan sebuah isyarat terciptanya sebuah bola tangan modern. Permainan "urania" yang dimainkan oleh orang-orang Yunani kuno (yang digambarkan oleh Homer dan Odyssey) dan Harpaston yang dimainkan oleh orang-orang Romawi yang bernama Claudius Galenus (130-200 Masehi). Sebagaimana dalam "Fangballspiel" atau permainan "tangkap bola" yang diperkenalkan dalam sebuah lagu oleh seorang penulis puisi Jerman bernama Walther Von der Volgelwiede (1170-1230 M), di mana sebuah keterangan tersebut merupakan tanda-tanda pasti yang biasa digambarkan sebagai bentuk kuno dari permainan bola tangan. Di Perancis, seorang yang bernama Rabelais (1494-1533) menggambarkan bentuk permainan bola tangan dengan "mereka bermain bola tangan menggunakan telapak tangan mereka”. Lebih jauh lagi, pada tahun 1793 masyarakat Inuit yang hidup di dataran hijau menggambarkan dan membuat ilustrasi permainan bola dengan menggunakan tangan. Pada

Volume 3, Nomor 1, Maret 2022 | 82 
tahun 1848 seorang administrasi olahraga Denmark memberikan izin untuk "permainan bola tangan" agar dimainkan di sekolah lanjutan di Ortup Denmark dan mendorong untuk menyertakan aturan dalam permainan bola tangan.

Federasi Bola Tangan Asia (Asian Handball Federation) terbentuk pada tahun 1974, pada waktu berlangsungnya Asian Games di kota Teheran. Kemudian pada tahun 1976 federasi ini dikukuhkan secara resmi di Kuwait. Namun bila membuka lembaran sejarah ternyata bola tangan yang dimainkan oleh 11 pemain, pernah mengisi acara pertandingan dalam Pekan Olahraga Nasional, tetapi hanya pada PON ke II yang diselenggarakan di Jakarta. Peserta pertandingan pada waktu itu hanya terdiri dari 4 daerah yaitu: Jakarta Raya, Jawa Barat, Jawa tengah dan Jawa timur. Setelah itu, belum ada usaha serius dari pihak-pihak tertentu agar bola tangan bisa dipertandingkan lagi pada Pekan Olahraga Nasional (Yulita, 2016). Selain pada PON, permainan bola tangan juga pernah mengisi acara dalam Pekan Olahraga Mahasiswa keV yang diselenggarakan di Medan pada tahun 1960. Akan tetapi permainan bola tangan 11 pemain ini hanya bertahan, permainan bola tangan 11 pemain mengalami kemunduran yang akhirnya menjadi tidak populer lagi. Tapi upaya untuk mendirikan induk organisasi seharusnya tetap ada, supaya permainan bola tangan mengalami kemajuan di masa yang akan datang (Rohman, 2018).

Bola tangan adalah olahraga beregu di mana dua regu dengan masing-masing 7 pemain (6 pemain dan 1 penjaga gawang) berusaha memasukkan sebuah bola ke gawang lawan. Permainan ini mirip dengan sepak bola, tapi cara memindahkan bola adalah dengan tangan pemain, bukan kaki (Popalri \& Fikri, 2019). Lapangan bola tangan berukuran $50 \mathrm{~m}$ x $20 \mathrm{~m}$ dengan garis pemisah di tengah dan gawang di tengah kedua sisi pendek. Di sekeliling gawang dibuat garis untuk menandai daerah yang hanya boleh dimasuki penjaga gawang. Bola yang digunakan lebih kecil dari bola sepak. Handball dimainkan selama 2 x 30 menit. Penalti dilakukan dari jarak 29 meter. Handball juga dipertandingkan di Olimpiade. Kiper bola tangan adalah pemain paling defensif di timnya. Tugas utamanya adalah mencegah tim lain mencetak gol. Sebuah tim harus menunjuk satu pemain di lapangan sebagai penjaga gawang. Namun, seorang kiper dapat beralih ke pemain lapangan kapan saja selama pertandingan. Untuk melakukan ini, dia perlu diganti dan mengganti seragam kipernya menjadi seragam pemain lapangan. Seorang pemain lapangan dapat mengambil posisi penjaga gawang dengan cara yang sama. Aturan 5 "Penjaga Gawang " mengatur semua aturan yang berkaitan dengan kiper dan seperangkat aturan khusus tentang area gawang. Di dalam area ini penjaga gawang 
Jurnal Abdimas Kartika Wijayakusuma ISSN 2716-3512 (Online) ISSN 2721-0367 (Print)
This work is licensed under a Creative Commons

Attribution-ShareAlike 4.0 International License.

diperbolehkan menyentuh bola dengan setiap bagian tubuhnya untuk menangkis bola. Selain itu, beberapa aturan tidak berlaku untuk kiper di dalam area gawang (Budi dkk., 2019).

Permainan bola tangan belum berkembang pesat seperti olahraga permainan sepakbola, bola basket dan bola voli. Hal ini dikarenakan kurangnya sosialisasi serta minimnya fasilitas dan perlengkapan yang dapat digunakan dalam permainan bola tangan, sehingga permainan ini kurang diminati oleh sebagian masyarakat, terutama para siswa di sekolah (Syahrial \& Fatimah, 2020). Dalam garis besarnya, teknik dasar permainan bola tangan yang akan dipelajari pada pengabdian ini terdiri dari teknik menggiring bola (dribbling), mengoper bola (passing), menangkap bola (catch), dan menembakkan bola (shooting). Seluruh teknik dasar tersebut akan dijelaskan kepada siswa dengan bagiannya masing-masing disertai dengan video serta praktik yang membuat teknik tersebut lebih memudahkan dipahami. Sosialisasi pada siswa tentang permainan bola tangan bertujuan untuk menambah wawasan serta keterampilan siswa tentang permainan bola tangan serta membuka peluang untuk berprestasi di cabang olahraga bola tangan.

\section{Metode}

Metode pendekatan dalam kegiatan ini menggunakan metode demonstrasi, presentasi dan diskusi. Subjek dalam kegiatan ini adalah siswa-siswi SMP Muhammadiyah Pekajangan yang berjumlah 30 siswa kelas IX. Metode ceramah digunakan untuk menjelaskan kepada siswasiswi mengenai olahraga bola tangan (handball) mulai dari sejarah, pengertian dan peraturan permainan handball. Ceramah ini dilakukan secara langsung di SMP Muhammadiyah Pekajangan.

Dalam pelaksanaan kegiatan ini pelaksana membagi beberapa tahapan atau prosedur kerja, yaitu; tahap 1 merupakan permohonan izin kepada kepala sekolah SMP Muhammadiyah Pekajangan, penentuan waktu dan tempat pelaksanaan, tahap 2 yaitu pemberian materi mengenai olahraga bola tangan (handball), dan tahap 3 adalah evaluasi kegiatan pengabdian.

\section{Hasil dan Diskusi}

Kegiatan sosialisasi permainan tradisional ini dilakukan oleh tim pengabdian kepada masyarakat yang beranggotakan 5 orang. Kegiatan ini dilaksanakan pada tanggal 26 Januari 2022 di SMP Muhammadiyah Pekajangan yang dilakukan secara luring. Dalam melakukan sosialisasi dilakukan secara bertahap, pendekatan kepada siswa SMP Muhammadiyah Pekajangan, kegiatan ini dilakukan dengan memperkenalkan diri kepada siswa. Sosialisasi ini 
Jurnal Abdimas Kartika Wijayakusuma ISSN 2716-3512 (Online) ISSN 2721-0367 (Print)
This work is licensed under a Creative Commons Attribution-ShareAlike 4.0 International License.

dilakukan dengan memberikan materi terlebih dahulu mengenai peranan olahraga secara umum dan olahraga handball secara khusus yang meliputi pengertian, sejarah dan cara bermain handball. Dalam pemberian materi tersebut, pelaksana kegiatan menekankan bahwa olahraga merupakan suatu aktivitas yang perlu dilakukan, karena olahraga ini mempunyai peranan penting dalam menjaga tubuh, kesehatan pada manusia. Tentunya dalam melakukan olahraga juga tidak perlu dilakukan selama berjam-jam, dan olahraga juga tidak hanya sebatas berlari, bersepeda dan beberapa olahraga umum lainnya. Olahraga bola tangan (handball) juga termasuk dalam olahraga yang memiliki banyak manfaat bagi tubuh. Olahraga ini sudah mulai berkembang di berbagai daerah namun masih perlu sosialisasi secara menyeluruh agar olahraga bola tangan ini semakin dikenal di semua kalangan. Aktivitas olahraga yang dilakukan oleh anak-anak lebih banyak pada aktivitas ringan seperti bersepeda atau bermain sepak bola. Seperti yang terjadi pada siswa-siswi kelas 9 di SMP Muhammadiyah Pekajangan, rata-rata dari mereka lebih suka bermain sepakbola atau futsal.

Penyampaian materi dilakukan dengan menyenangkan sehingga siswa tertarik namun tetap memperhatikan dengan fokus. Penyampaian materi ini juga bertujuan untuk memberikan informasi kepada siswa mengenai apa saja permainan dan teknik-teknik dalam olahraga handball. Gambar 1 memperlihatkan penyampaian materi di kelas. Hasil kegiatan yang telah dicapai sosialisasi handball yaitu pengetahuan dan pemahaman siswa-siswi SMP Muhammadiyah Pekajangan mengenai olahraga handball yang dilakukan dalam bentuk presentasi.
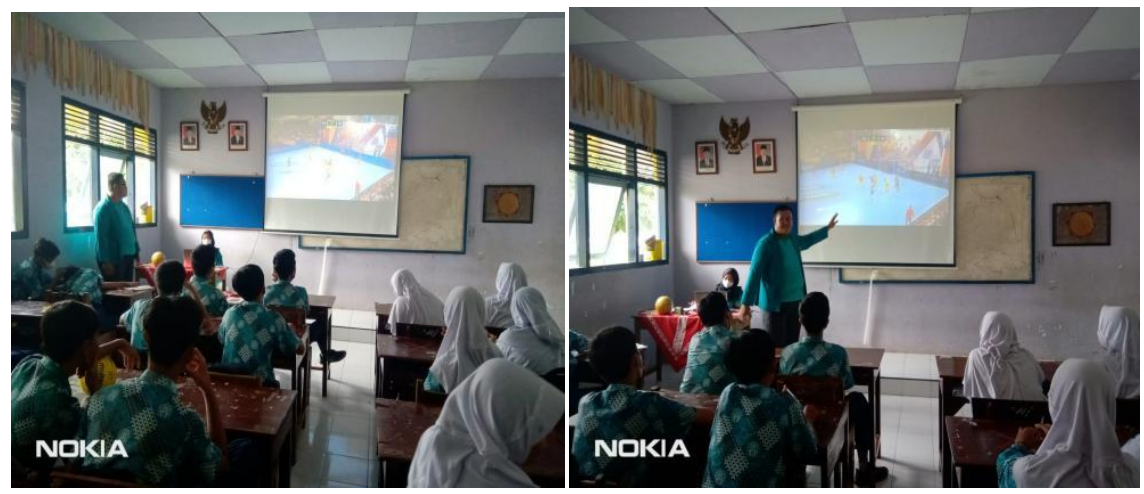

Gambar 1. Penyampaian Materi Handball

Setelah diberikan pemahaman secara teori, pengabdi melakukan demonstrasi mengenai teknik-teknik yang ada dalam permainan handball. Pengabdi juga memberi kesempatan pada beberapa siswa untuk mempraktikkan beberapa teknik olahraga handball seperti yang telah didemonstrasikan seperti diperlihatkan pada Gambar 2. Hal ini bertujuan agar siswa-siswi 
lebih menguasai keterampilan olahraga handball.
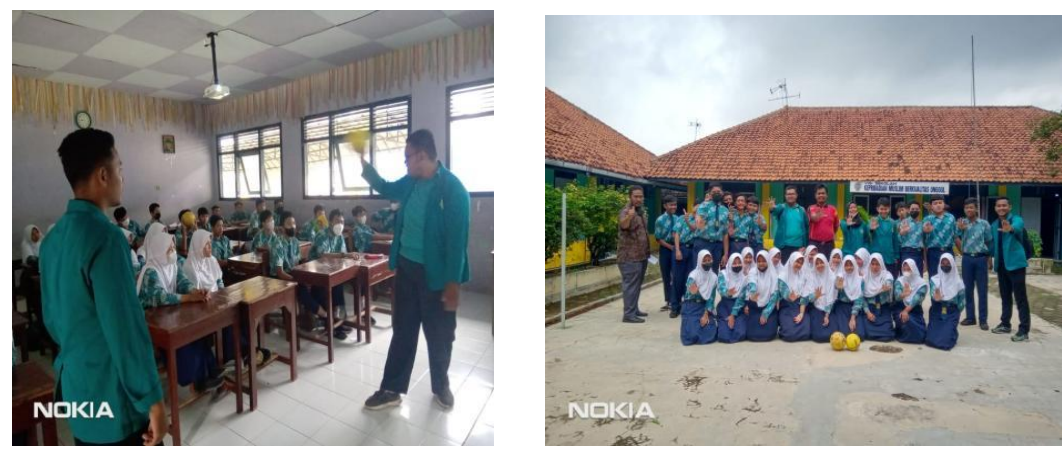

Gambar 2. Demonstrasi Teknik Handball

Evaluasi terhadap kegiatan dilakukan dengan menyebarkan angket setelah penyampaian materi. Siswa-siswi terlihat antusias pada saat penyampaian materi serta dilaksanakannya demonstrasi, tapi terdapat beberapa siswa yang kurang memperhatikan. Hal ini dikarenakan kurang optimalnya kegiatan demonstrasi karena kurangnya prasarana seperti lapangan. Selain itu kegiatan praktik olahraga di lapangan juga ditiadakan selama masa pandemi sehingga demonstrasi tidak bisa berjalan secara maksimal. Berdasarkan data yang diperoleh dari angket yang diisi oleh peserta, nilai rata-rata kepuasan siswa terhadap kegiatan yang telah dilaksanakan sebesar $85 \%$ seperti diberikan dalam Tabel 1.

Tabel 1. Tingkat Kepuasan Siswa

\begin{tabular}{|c|c|c|c|c|c|}
\hline Kategori & $\begin{array}{c}\text { Jumlah } \\
\text { siswa }\end{array}$ & Puas & $\begin{array}{c}\text { Kurang } \\
\text { Puas }\end{array}$ & $\begin{array}{c}\text { Tidak } \\
\text { Puas }\end{array}$ & Persentase \\
\hline $\begin{array}{c}\text { Minat siswa dalam } \\
\text { sosialisasi olahraga bola } \\
\text { tangan (handball) }\end{array}$ & 30 & 25 & 5 & 0 & $85 \%$ \\
\hline
\end{tabular}

\section{Kesimpulan}

Permainan bola tangan merupakan olahraga yang mulai berkembang di berbagai daerah namun masih perlu sosialisasi secara menyeluruh agar olahraga bola tangan ini semakin dikenal di semua kalangan. Sosialisasi handball dilakukan dengan metode ceramah dan demonstrasi agar tidak hanya terjadi peningkatan secara kognitif namun juga psikomotorik. Berdasarkan angket kepuasan yang diberikan kepada seluruh peserta diperoleh bahwa $85 \%$ siswa merasa puas. Dalam hal ini, hasil yang telah dicapai dalam sosialisasi handball yaitu meningkatnya pengetahuan dan pemahaman siswa-siswi SMP Muhammadiyah mengenai olahraga handball yang dilakukan dalam bentuk presentasi materi serta meningkatnya keterampilan dasar teknik permainan handball. 


\section{Ucapan Terima Kasih}

Ucapan terima kasih disampaikan kepada Kepala Sekolah SMP Muhammadiyah Pekajangan yang telah memberikan izin untuk melaksanakan kegiatan pengabdian kepada masyarakat ini serta siswa kelas IX yang telah mengikuti kegiatan sosialisasi dari awal hingga akhir dengan antusias.

\section{Daftar Referensi}

Budi, D. R., Hidayat, R. \& Febriani, A. R. 2019. Penerapan Pendekatan Taktis Dalam Pembelajaran Bola Tangan. JUARA : Jurnal Olahraga, 4(2), 131-139.

Iskandar, I., Suyuti, A. \& AM, A. M. J. 2020. PKM Pembelajaran Konsep Gerak Dasar Bolatangan Pada Murid SDN Batulaccu Makassar. PENGABDI: Jurnal Hasil Pengabdian Masyarakat, 1(1), 57-61.

Mulyani, G. D. 2017. Pengaruh Pengajaran Handball Like Games Terhadap Penguasaan Keterampilan Gerak Dasar Lempar Tangkap Dalam Pembelajaran Penjas Sekolah Dasar. Jurnal Pendidikan Jasmani Dan Olahraga, 2(1), 69.

Popalri, P. \& Fikri, A. 2019. Validitas Modul Bola Tangan Bagi Mahasiswa Pendidikan Jasmani Kesehatan dan Rekreasi STKIP PGRI Lubuklinggau. Gelanggang Olahraga: Jurnal Pendidikan Jasmani Dan Olahraga (JPJO), 3(1), 89-95.

Rahayu, R., Subroto, T., \& Budiman, D. 2020. Implementasi Model Pembelajaran Pada Olahraga Permainan Bolatangan. Physical Activity Journal, 1(2), 107.

Rohman, U. 2018. Metode Pembelajaran Permainan Bola Tangan Dengan Menggunakan Latihan Ladder Drill Hop Scotch Pengaruhnya Terhadap Kemampuan Agility Bermain Bola Tangan. Buana Pendidikan: Jurnal FKIP Unipa Surabaya, XIV(26), 136-143.

Setiawan, A. \& Rahmat, A. 2018. Pengaruh Pembelajaran Bola Tangan Terhadap Perilaku Sosial Siswa. Jurnal Pendidikan Jasmani Dan Olahraga, 3(1), 89.

Sumarsono, A., Anisah, A. \& Iswahyuni, I. 2019. Media interaktif sebagai optimalisasi pemahaman materi permainan bola tangan. Jurnal Pendidikan Jasmani Indonesia, 15(1), $1-11$.

Syahrial, F. \& Fatimah. 2020. Implementasi Model Pembelajaran Pada Olahraga Permainan Bola Tangan pada Siswa Tingkat SMP 3 Praya Kecamatan Praya Lombok Tengah NTB. Physical Activity Journal, 1(1), 73-79.

Yulita, Y. 2016. Pengembangan Permainan Bola Tangan Gawang Pantul Untuk Pembelajaran Penjasorkes. Jurnal Pendidikan Jasmani Kesehatan dan Rekreasi (Penjaskesrek) 3(2): 24-31.

Volume 3, Nomor 1, Maret 2022| 87

Sosialisasi Olahraga Handball di SMP Muhammadiyah Pekajangan 